\title{
A PREVENÇÃO QUATERNÁRIA E O MICROBIOMA DE CRIANÇAS E ADOLESCENTES
}

\author{
Júlia Maria Guilherme Ribeiro Antunes \\ Médica e Médica Dentista \\ Instituto Universitário Egas Moniz \\ Prof. Auxiliar \\ julia@antunes.net
}

Fecha de Recepción: 26 Mayo 2019

Fecha de Admisión: 25 Septiembre 2019

\section{RESUMO}

Os cerca de 40 triliões de bacterias que fazem parte do nosso corpo, constituindo o microbioma, passaram durante longo tempo "despercebidos", mas actualmente estão a provocar uma revolução na explicação de doenças, como asma, autismo, cancro, diabetes, obesidade, sindrome metabólico, sindrome de fadiga crónica entre outros.

A fobia antibiótica nascente, é orquestrada pelos profissionais de saúde, e com razão, pois quando uma criança ou um adolescente é medicado com antibiótico, erradamente muitas vezes, pois trata-se de infeções viricas, o que estamos a fazer é modificações no microbioma, que podem, aí sim, levar ao aparecimento de verdadeiras doenças!

Á intensa medicalização da vida diária, que transforma gente saudável em doentes crónicos, Barski, em 1988, chamou-Ihe o "paradoxo da saúde" que alimenta mercados que valem biliões de dólares como os da da ritalina e oxycodona!

A prevenção quaternária veio nos últimos anos dar uma esperança a todos aqueles que desejam um outro olhar sobre a problemática da saúde/ doença, actualmente enquadrada nos actuais desenvolvimentos sobre Microbioma

Palavras chave: prevenção quaternária; medicina preventiva; microbioma.

\section{ABSTRACT}

Quarternary prevention and the microbioma of children and adolescents. The approximately 40 trillion bacteria that are part of our body, constituting the microbiome, have long gone unnoticed, but they are currently sparking a revolution in explaining diseases such as asthma, autism, cancer, diabetes, obesity, syndromes. metabolic, chronic fatigue syndrome and others.

The nascent antibiotic phobia is orchestrated by health professionals, and rightly so, because when a child or adolescent is treated with antibiotics, often wrongly, because these are viral infections, what we are doing is modifications in the microbiome, which can then lead to the appearance of true diseases! 


\section{A PREVENÇÃO QUATERNÁRIA E O MICROBIOMA DE CRIANÇAS E ADOLESCENTES}

The intense medicalization of daily life that turns healthy people into chronically ill people, Barski, in 1988, called it the "health paradox" that fuels billions of dollars worth of markets like ritalin and oxycodone!

Quaternary prevention has in recent years given hope to all those who wish to take another look at the health / disease issue currently framed in current developments on microbiome.

Keywords: quaternary prevention; preventive medicine; microbiome.

\section{INTRODUÇÃO}

0 Microbiota humano, por volta dos 2 anos estará estabelecido, influenciado por muitos fatores, como o tipo de parto, que se for eutócico, permitirá o contato com a microbiota fecal da mae, o tipo de leite, materno ou industrializado, contaminação ambiental, sistema imune, as características genéticas, trata-se de um ecossistema altamente complexo, rico em bactérias anaeróbias que irá influenciar e determinar a saúde do indivíduo ao longo da vida (Wall et all.,2009).

A colonização do trato gastro intestinal infantil é fundamental para a saúde do bébé hoje e do futuro adulto, amanhã. As bactérias entéricas apresentam atividade antibacteriana, imunomoduladora e nutricional, podem ser benéficas como as Bifidobactérias e Lactobacilos, nocivas como 0 Clostridium spp.(Santos; Varavalho, 2011).

Micro-organismos vivos que ao serem administrados em quantidade adequada regularizam a microbiota depois do uso de um antibiótico, estimulam o sistema imunológico, a permeabilidade intestinal, protegem de invasores patogénicos, denominam-se probióticos e prebióticos aqueles componentes alimentares que estão capacitados para modificar o microbiota, de forma a aumentarem acentuadamente 0 volume de bactérias benéficas (Morais \&jacob, 2006).

A alimentação rica em probióticos e prebióticos, parece fortalecer a simbiose deste ecossistema com as células do hospedeiro (Saad, 2006).

Sabemos hoje, e cada vez mais, que a utilização vulgar de antibióticos em excesso, ou incorretamente administrados, induzem seleção natural de bactérias nocivas ao microbiota intestinal, influenciando negativamente a saúde do hospedeiro mas tão desejados pelos pais para a mínima moléstia manifestada pelos seus pimpolhos!!

\section{DESENVOLVIMENTO}

A mae é a primeira fonte de microorganismos da criança, os fatores imunológicos presentes no leite materno, induzem a inibição de bactérias patogénicas e o microbiota comensal é rico em bifidobactérias. A contaminação ambiental regula

a colonização intestinal e é variável segundo o tipo de pais e mesmo o tipo de Continente (Andrade, 2010).

0 microbioma garante a resistência á colonização microbiana indesejável, bem como fatores anatómicos e fisiológicos, salivação, secreção de imunoglobulina IgA, produção de ácidos gordos , descamação da mucosa, motilidade gastrointestinal.

Há também produção de vitaminas do complexo B e de vitamina K, muito importantes para 0 metabolismo do indivíduo, são produzidas no colon por Propionibacerium, Fusobacterium, Bifidobacterium, Lactobacilus, Clostridium, Enterobacterium, Veillonella, Enterococcus e Estreptococcus (Barbosa et all 2010)

Criancas e adolescentes, com desiquilibrio da microbiota intestinal, podem apresentar doenças autoimunes ou atópicas (Francino, 2014)

Perante a presença de agentes patogénicos, o microbiota normal elimina-os, mas se houver uso de antibióticos, tal pode não acontecer e desenvolverem-se estirpes como Salmonella spp, Vibrio ou Estafilococcus.(Carlet, 2012). 
A má digestão, 0 abuso de laxantes, o excessivo consumo de alimentos crus, a presença de tóxicos ambientais, a qualidade do estado imunológico representam agressões ao microbioma. Tratamentos continuados no tempo com antibióticos, selecionam bactérias, que se tornam altamente resistentes, impossíveis mesmo de eliminar!!

Nos hospitais os problemas começaram com Klebsiella pneumoniae e pela Echerichia Coli, altamente resistentes a tudo e a todos os antibióticos existentes !! São bactérias multi drogas resistentes (MDR), aos betalactâmicos, fluoroquinolonas, aminoglicosídeos.

Sabemos hoje que o uso frequente de antibióticos, interfere na saúde imunológica de adultos e crianças, onde encontramos casos de enterocolite necrosante, particularmente em recém nascidos e naqueles cujas mães tomaram antibióticos durante a gravidez (Francino, 2014).

A enterocolite necrosante, atopia, doenças inflamatórias intestinais, em recém nascidos são multifatoriais, existe imaturidade intestinal, imunológica, infeção, hipoxia, microbiota alterado (Paixao, 2016)

Os probióticos e prebioticos, foram apelidados de alimentos funcionais nos anos 80, pelos Japoneses, confeririam benefícios em saúde aos seus utilizadores, reduzindo o risco de doenças crónicas (Raizel et all, 2011).

Na prevenção e tratamento das diarreias secundarias á utilização de antibióticos, os probióticos tem interesse, como a Saccharomyces boulardi, as bifidobactérias, entre outros.

0 sucesso dos prebióticos, relaciona-se com o facto de estimularem o crescimento de bactérias não patogénicas, caso da lactulose, xilitol, inulina.

Fortalecer um microbiota problemático, já se conhecia no séc IV na literatura chinesa, na obra de Gen Hong onde se preconizava a utilização de fezes humanas para tratar a diarreia, bem como a gastroenterite grave, hoje 0 transplante de microbiota fecal (TMF) é uma realidade e um sucesso garantido de 93\% nas infeções por Clostridium difficile (Kapel, 2015)

Alimentacão, estilo de vida e medicamentos, em qualquer idade têm impacto na saúde e na doença. Como poderemos contribuir para desmedicalizar a sociedade e melhorar a nossa qualidade de vida ?Conhecendo e operacionalizando a prevenção quaternária!!

A Prevenção Quaternária operacionaliza-se com a acção dos profissionais de saúde, com mais espirito critíco, com a ética da negativa com a prática do wait and see com mais cepticismo, face á avalanche de tratamento e prevenção, do sec. XXI.

linicialmente eram essencialmente os Médicos de Familia bem como os diferentes sistemas de saúde, os caminhantes que, contextualizados na antiga ética do "primum non nocere" (first do no harm) versus "primum succurere" (first hasten to help), que deram voz a esta filosofia elevando-a na prática clinica diária da equipe multidisciplinar (Antunes, 2016).

Podemos observar hoje, um conhecimento e reconhecimento cada vez maior, dos vários profissionais das diferentes àreas da medicina no que respeita á Prevenção Quaternária. É necessário lançar âncora nesse mar de infinitos diagnósticos, para não sermos arrastados para a corrente do overdiagnosis e overmedicalization, overtreatment, overscreenings, overinformation! (Heath, 2013).

\section{CONCLUSÃO}

As influências da prescrição são enormes e muito DESCONHECIDAS, por enquanto. Assim, a prudência manda, que no mínimo, perante as evidências atuais, um pouco por todo o mundo, seja evitada a todo o custo a SOBREMEDICALIZAÇÃO das atuais sociedades.... a bem das vindouras !! 


\section{A PREVENÇÃO QUATERNÁRIA E O MICROBIOMA DE CRIANÇAS E ADOLESCENTES}

\section{REFERÊNCIAS BIBLIOGRÁFICAS}

Andrade, A. M. D. S. D. (2011). Microflora Intestinal: uma Barreira Imunológica Desconhecida(2009\2010).Dissertacao .Porto.

Antunes, J. M. R. (2016). Lógicas, racionalidades e contextos dos itinerários de saúde/doença de Universitários. International Journal of Developmental and Educational Psychology. Revista INFAD de Psicología., 2(1), 221-232.

Barbosa, F. H. F., dos Santos Martins, F., de Lima Barbosa, L. P. J., \& Nicoli, J. R. (2010). Microbiota indígena do trato gastrintestinal. Revista de Biologia e Ciências da Terra, 10(1), 78-93.

Francino, M. P. (2014). Early development of the gut microbiota and immune health. Pathogens, 3(3), 769-790.

Heath I.(2013) Overdiagnosis: when good intentions meet vested interests: an essay by IonaHeath. BMJ. 347:f6361. https://doi.org/10.1136/bmj.f6361

Barsky, A. J. (1988). The paradox of health. New England Journal of Medicine, 318(7), 414-418.

Carlet, J. (2012). The gut is the epicentre of antibiotic resistance. Antimicrobial resistance and infection control, 1(1), 39.

Dos Santos, T. T., \& Varavallo, M. A. (2011). A importância de probióticos para o controle e/ou reestruturação da microbiota intestinal. Revista científica do ITPAC, 4(1), 40-49.

Heath I.(2013) Overdiagnosis: when good intentions meet vested interests: an essay by IonaHeath. BMJ. 347:f6361. https://doi.org/10.1136/bmj.f6361

Morais, M. B. D., \& Jacob, C. M. A. (2006). 0 papel dos probióticos e prebióticos na prática pediátrica. Jornal de Pediatria.

Paixão, L. A., \& dos Santos Castro, F. F. (2016). Colonização da microbiota intestinal e sua influência na saúde do hospedeiro. Universitas: Ciências da Saúde, 14(1), 85-96.

Saad, S. M. I. (2006). Probióticos e prebióticos: o estado da arte. Revista Brasileira de Ciências Farmacêuticas, 42(1), 1-16.

Raizel, R., Santini, E., Kopper, A. M., \& REIS FILHO, A. D. (2011). Efeitos do consumo de probióticos, prebióticos e simbióticos para o organismo humano. Ciências Saúde, 4(2), 66-74.

Wall, R., Ross, R. P., Ryan, C. A., Hussey, S., Murphy, B., Fitzgerald, G. F., \& Stanton, C. (2009). Role of gut microbiota in early infant development. Clinical medicine. Pediatrics, 3, CMPed-S2008. 